\title{
A Simple Analysis on the Combination of Modernism and Regional Culture in the Construction by Geoffrey Bawa
}

\author{
Weihua $\mathrm{Hu}$ \\ Hubei University of Education \\ Wuhan, China
}

\begin{abstract}
In the process of globalization, there are many urgent problems faced by construction and design art. The fierce collision of modernist art and regional culture happened in construction brings unique wisdom for human beings. Geoffrey Bawa, coming from beautiful Sri Lanka, was regard as the most prominent contemporary architectural designer in Asia. In beautiful Sri Lanka, he designed a great number of excellent architectural works. He combined local tradition and epoch characteristics perfectly in his works, giving the architectures original and fresh vitality. In this paper, the author will learn from Geoffrey Bawa's architectural works to study and research the dynamic integration of regional culture and modernist art in modern construction.
\end{abstract}

Keywords-Geoffrey Bawa; modernist architecture; regional architecture

\section{INTRODUCTION}

In today's construction design, the conflict between locality and globalization and modernization becomes the first question faced and to be solved by every country and region. For construction design, an obvious characteristic of its globalization and modernization is that the construction style and concept are the same in modern construction culture. Architectures all over the world are similar, just as they are designed by a certain person. The inundation of such architectural culture is no doubt harmful to world construction development. Countries and regions with rich historical culture can hardly show their advantages under the cover of numerous modernist architectures, so the individual regional culture is challenged seriously in the process of modernization.

Sri Lanka is a beautiful country, from which the most productive and influential architectural designer Geoffrey Bawa comes. Geoffrey Bawa's construction projects are mainly located in Sri Lanka and some tropical zones in Asia. Before the latest architectural design concepts "sustainable development" and "climate adaptability" appear, he has begun to adapt to local architectural elements, materials, construction methods and ideas in design practice. At the same time, he thinks that the architectures should give inside people space and visual experience, which is much more important than concrete buildings. Therefore, his works are always adapted to local climate and landscape. Carefully arrayed space as well as its style blurs the limit of the indoor and outdoor space. Geoffrey Bara's uniqueness is that he refined and extracted the quintessence and essence of the natural environment and cultural tradition of Sri Lanka with the help of his understanding and perception to modern art.

For this reason, his can blend local regional culture and modern art characteristics perfectly in his architectural works, which conforms to the background and era requirement, so it is still full of vitality today. Researching Geoffrey Bawa's design thought and works will provide valuable reference for China's regional architecture concept and practice.

\section{THE SPREAD OF THE MODERN ARCHITECTURE}

From the 1930s onwards, modernism spread rapidly to the world and became the dominant trend in modern architecture in the mid-20th century. Modernist architecture with "functionalism" as the main design principle was popular in the context of World War II. It emphasized that construction must take the road of industrialization, which highlighted the decisive role of technology in architecture at the same time. The characteristics showed by the texture of the material itself and the general feeling of quantity as well as space consciousness of structure were also valued in modern architecture. Art performance focused on surface and body of the architectural shape and advocated the beauty of the function and structure, so it consciously simplified the appearance of the building. Therefore, it can be said that modernist architecture created a set of artistic expression techniques opposing classicism on the basic of the principle combining function, material and artistic expression.

Hereafter, a large number of newly built industrial buildings, commercial buildings, cultural and educational buildings and large-scale residential buildings took root in countries and cities all over the world. They almost all got rid of the traditional style and had significant modern architectural features. Even the commemorative buildings and government buildings that best reflect the cultural characteristics of the region abandoned the traditional architectural form used in the past and showed a very disruptive face for people. The most fundamental reason for this situation was not the social trend of that time, but the objective law in line with building development based on 
basic principles of modern architecture. Therefore, the modernist architecture became the world's mainstream in the field of architecture at the time.

Today's modernist architecture also presents a trend of diversification. The main reasons are the following two aspects: First, in the mid-20th century, the world's science and technology and industry developed by leaps and bounds, so a few countries greatly improved the material quality of life. People in the new social environment put forward new demands on architecture and architectural art. Second, the modernist architecture, which was born in Western European countries, was changed in the process of a world-wide spread, combining with the local natural and humanistic environment.

Therefore, architectural designers of this new era began to chase better performance of the architectural image, they no longer followed the believes such as "form serves to function", "less is more", "decoration is evil" and "residence is the machine to live", and brought forth the consideration that the building should surpass the function and technology and that architectures should have the appropriate decoration and absorb the traditional architectural techniques and styles to a certain extent to give the modernist architecture local characteristics.

\section{REGIONAL ARCHITECTURES}

\section{A. The Basic Characteristics of Regional Architecture}

First, responding to local landforms, landscape and climate

Second, utilizing local materials, energy and construction technology

Third, absorbing architectural culture achievement including architectural culture achievement

Fourth, being economic and distinctive from other regions

Other than the above mentioned characteristics, the current regional architecture learns more from materials, technical means and construction methods of modern architecture, showing the updating concept of regional architecture.

\section{B. Regional Architecture and Climate}

Climate, as the most fundamental and universal factor of all natural factors that influence and determine the architectural style of the area, determines the most fundamental and unchangeable part of the architectural form, which is the highest priority to measure the rationality. When other natural and social factors make buildings of various regions develop differently and form kinds of strange styles, the buildings under the same climate conditions on the world incredibly show the basic conformance.

Different types of climate make the architectural form of each area greatly different, and reflect in various aspects of the building. Such as: building materials, construction technology, construction practices and basic structure and so on. Local regional culture has an intuitive effect on these differences, but the key to these differences is that between the climate partitions. In order to adapt to local climatic conditions, ancient ancestors in their respective habitat areas naturally chose architectural forms that in line with local life and production methods. In a similar climate environment, people from different regions often make the same choices, so the regional architectural forms in the world have a considerable possibility to be in common.

\section{Regional Characteristics Make the Architectures Return to Nature}

The basic characteristics of modernist architecture, such as the choice of building materials, high industrial construction methods and processes make it produce irreversible damage to natural ecological environment in its development process. Reducing environmental pollution and energy consumption in design, construction and using process of modern architecture has become an inevitable problem to be solved in new era.

For this problem, the regional architecture has a rare and valuable solution in its design concept. Using local architectural materials; adopting local architectural technology; utilizing traditional construction methods, can undoubtedly improve energy use efficiency in the entire life cycle of architectures. For the vast number of developing countries that lack of energy-saving technology, the valuable characteristics of regional architecture can play its role at this time. It is an excellent choice for architectural design to return to innocence.

\section{GEOFFREY BAWA AND HIS ARCHITECTURAL DESIGN}

Geoffrey Bawa used to be a professional lawyer and entered architectural field because of individual interest. In 1947 , he bought a rural villa. When building the personal garden, he showed a great interest to architecture design. In 1950s, he went to Architectural Association School of Architecture for further study. From its early projects we can see its value orientation of architectural education. For example, Teaching Buildings of Bishop College (1960) and St. Thomas College (1957) and Colombo Automobile Association Office Building (1959) all showed the characteristics of modern architecture in tropic zones. However, in the initial stages of his design career, Bawa questioned the conventional routines of Sri Lanka's prevailing design. In practice, he refused to blindly use reinforced concrete and rebar, which stood for modernism, but tried to follow a more convenient local construction technology.

Bawa focused on using ancient and traditional technology and materials of Sri Lanka to meet the possibilities and needs of modern architecture. The design of the Villa Berawa in Polon (1963) was shaped by these factors. In 1965, Bawa undertook the first hotel building project, which was located in the Blue Lagoon near Negombo. Bawa applied material combination in his own style to the project, which was used in public buildings for the first time. The so-called "Bawa style" included the 
following features: concrete frame, wall plaster, wooden screen, wooden truss slope roof and deep roof covered with the Portuguese-style semicircle-shaped tile.

The Triton hotel built in 1980s, Ruhuna university campus and Sri Lankan Parliament Bldg complex located in Sri Jayawardenepura Kotte, all these projects' scale greatly surpassed any other projects of the company. Bawa always paid attention to building trails and was good at organizing continuous space and led people to move in the specified way inside the architectures. Buildings designed by Bawa, although most of them were arranged in the plane according to linear, its combinations of space didn't abide by the horizontal and vertical principles and they were handed richly and vividly, exquisite and beautiful. For example, he often used the oblique-line type dui jing technique to create dramatic feelings. Architectural space was seen as scene configuration of specific situations. While the external space was intentionally showed or implicitly set off, associating with the architecture. The Bawa's principle was: "hide" and "exposure" are equally important.

In essence, the architectural structure of Bawa is mainly used to create space, and then give space to cultural significance and spiritual connotation, so its buildings are rarely decorated. The architectures are hidden in environment or play second fiddle, as the scene frame. Bawa thinks that architectures shouldn't prevent people from living and recreation and entertainment. Otherwise, they are not real buildings. Because of this, he never cares the architectural form and style. He believes that the internal space, relations between internal and external space as well as external space are more important, while the appearance of the building is only the result of the combined effect of the above factors.

As for choosing architectural style and pattern, he pursues "copinism" and is willing to learn from any source to get inspiration and experience. His architectures are economical and practical, especially adapted to the monsoon climate. He focuses on the organization of space, rather than the appearance of the form, so his buildings are often simple and plain, and the contact way of space is very delicate. In the 1960s, he focused on transforming and using native craft and materials; by the 1990 s, he tried to use vegetationcovered concrete and minimalist steel. All in all, Bava was obsessed with creating space experience, and its formal language was compromised and thought basing on history and aesthetics.

\section{EXAMPLES ANALYSIS OF GEOFFREY BAWA'S ARCHITECTURAL WORKS}

\section{A. The Osmund and Ena de Silva House}

The Osmund and Ena de Silva House is a milestone in the trend of modern architecture in Sri Lanka. How to deal with the relationship between tradition and modernity has been a major issue in architectural design, but Silva House firstly shows us the successful integration of the two. At first glance, the appearance of the building is not different from the traditional style of the South Asian city house. But when carefully observed, we can find its spatial quality and connectivity completely surpass the traditional approach. All the rooms in the house are open to each other and they are connected dynamically, showing the commonality of the modernist architecture. And the perfect blend of tradition and modernism is reflected in the selection of building materials and full utilization. The main body of the building uses a concrete frame, fully using its advantages of creating large span structures and open interior space. Materials for the shade and waterproof are local traditional building materials, which aim to withstanding the scorching sun and rainstorm and monsoon. Living space and open-air atrium integrate without traces, making the entire building space endless and unlimited.

Walls nearby street live blank and only garage doors and courtyards are decorated. The gate door is small, from which we can enter the antecourt, and then through a magnificent ancient temple door, via the aisle, we arrive at the central courtyard, where stands an ancient Jasminum grandiflorum. The whole house is divided into forecourt and backyard and connected by a spacious corridor. The ground floor of backyard is used for the main living space, and the bedroom is arranged upstairs. The alar parts of the buildings from the garage act as a service space, which is concealed on the side of the building.

The owners of the project are both enlightened and progressive and respect Sri Lanka's cultural and architectural traditions. The architects value tacit understanding for this point. The close cooperation between the two sides is finally crystallized into the highly innovative building.

\section{B. Kandalama Hotel}

The Kandalama Hotel is located near the cliffs and overlooks a large reservoir nearby built in the 4th century and a Sigiriya Palace Garden in 5th-century and the Buddhist temple of the Dumbria in 18th-century afar. Besides these precious archaeological sites, there are other places of historic interest and scenic beauty which attract many visitors, most of whom stay at the Kandalama Hotel.

The hotel avoids using magnificent building materials and decoration, but the shape of the layout is fine and complete, like a modern palace. The whole building is simple and plain, showing "dematerialization": structure of beam and column is simple and clear; it is covered by dense vegetation; stone floor is highly polished; pillars are painted black or white; floor sheet is plain. In this way, the architecture is hidden in the surrounding natural environment, as the background, it foils magnificent scenery of forest, wall rock and reservoir.

The carefully constructed axis of the landscape leads visitors to appreciate inside the architecture. The architecture itself is not an overwhelming place, but a vantage point and viewing platform for tourists. The building then turned into a series of banners and vertical frames to capture the best view between the mountains and rivers.

Visitors arrive at the hotel via an undeveloped forest trail when passing the arid region of deciduous leaves and forest. 
The vehicles can reach the fifth floor of the hotel from the wide ramps, and arrive at the entrance of the lobby which looks like a grotto. The steps are wide and made up of the mining stone. Up the stairs, we arrive at reception desk whose floor is decorated with the black polished stone. Through a tunnel carved in the rocks, we then enter the reception hall. The hall is tall and shrouded in the trees. Outside the reception hall, there is a terrace, in which builds a swimming pool, whose edge directly reaches the cliff. Living here, we can overlook the lake and reservoir as well as the Sigiriya rock. Floors above the entrance are all for the hotel public places; the below are for the rooms, constituting the hotel's main space, hidden and undetectable.

\section{CONCLUSION}

"Regional Modernist Architectural Design" is a specific generalization to the style of Geoffrey Bawa. Region and the world; tradition and modern; natural and artificial, these aspects that seem difficult to reconcile are blended in Bawa's design. The confrontation between modernism and regional culture is not uncommon in architectural works, they nor appear in some designs occasionally. For researches on today's architectural theory and environmental aesthetics, this phenomenon is an indispensable part in the process of resolving the era contradictions. The "blend of modernism and regional culture in architecture" described in this paper is a great attempt to answer this question.

Studying the works of Bawa, is a kind of pilgrimage and tribute to the forerunners, it contributes to development of China's environmental design in the era. Just as David Robertson says: there is few architect who combines local architectural tradition with modernist forms and emotions so harmoniously and happily like Geoffrey Bawa. Bawa as well as buildings designed by him has become the legend in local people's eyes. Both Geoffrey Bawa and his works are quite influential in the world.

\section{REFERENCES}

[1] Wang Yulin: regionalism architecture [M], Tianjin University Press.

[2] Liu Xiaoping: construction thought in the context of cross-cultural architecture [M], China Architecture \& Building Press.

[3] Qiu Dehua, Dong Zhiguo, Hu Ying: appreciation on construction art [M], Suzhou University Press

[4] Wang Lan: Sri Lankan national religion and culture [M], Kunlun Press.

[5] Wang Yuli: regional extension of modern construction campaign [D], Tianjin University

[6] Zhang Qifei: research on design thought and works of regional modernist master Geoffrey Bawa [D], Chongqing University

[7] Yang Tao: contemporary endemicity and Sri Lankan architect Geoffrey Bawa--- comment on three works of Geoffrey Bawa [J], World architecture, 2001 (12)

[8] David Robertson: early school design of Geoffrey Bawa [J], World architecture, 2003 (01)

[9] Wang Xiaodong: the remaining charm Geoffrey Bawa and the practice of regional architecture [J], South Architecture, 2008 (01)

[10] Xu Qianli: globalization and Regionalization---a modernistic problem [J], Architects, $2004(03)$ 